MPIKG Public Access

Author Manuscript

Published in final edited form as:

Yang, F., Zhang, S., Cheng, K., \& Antonietti, M. (2019). A hydrothermal process to turn waste biomass into artificial fulvic and humic acids for soil remediation. Science of the Total Environment, 686, 1140-1151. doi:10.1016/j.scitotenv.2019.06.045.

\title{
A hydrothermal process to turn waste biomass into artificial fulvic and humic acids for soil remediation
}

Fan Yang, Shuaishuai Zhang, Kui Cheng, Markus Antonietti
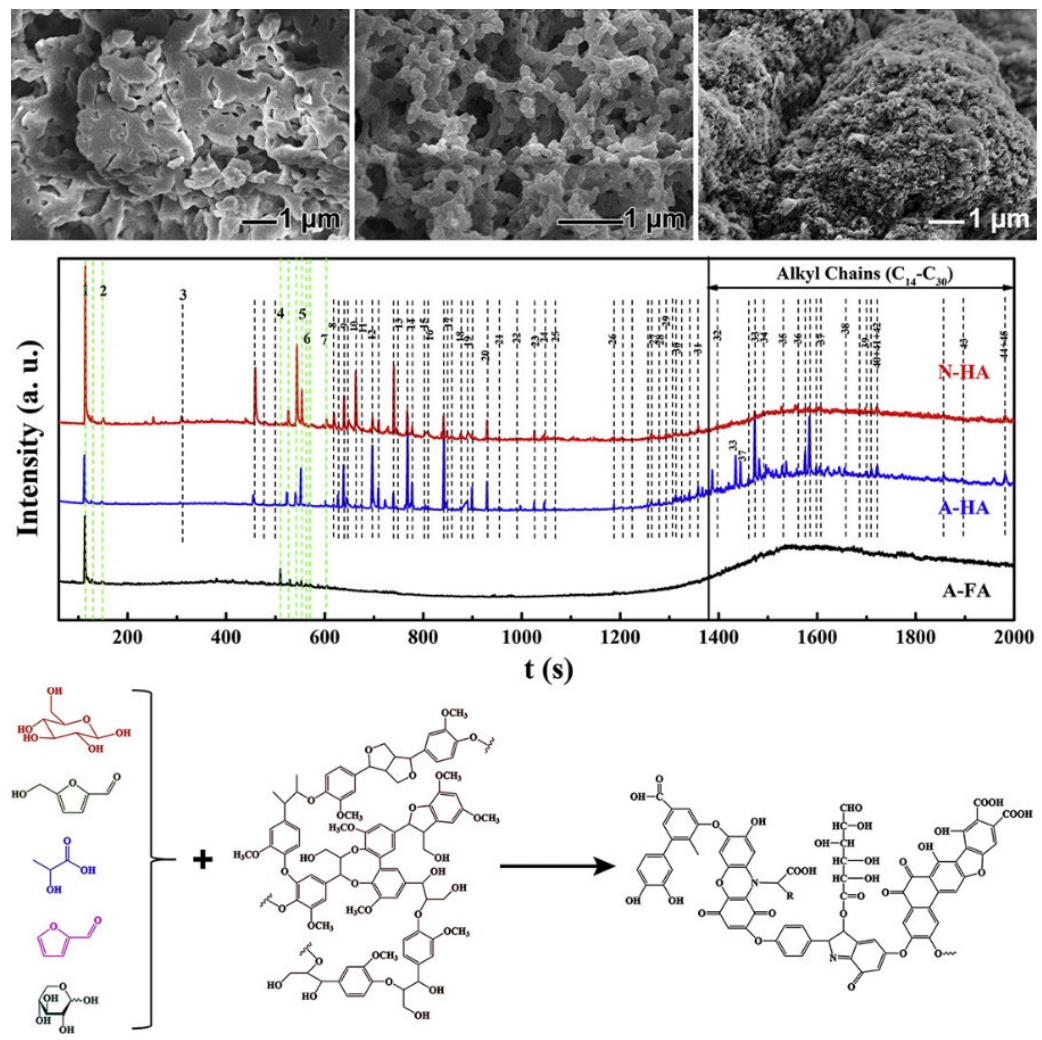

(C) 2021. This manuscript version is made available under the CC-BY-NC-ND 4.0 license http://creativecommons.org/licenses/by-nc-nd/4.0/ 
Title: A hydrothermal process to turn waste biomass into artificial fulvic and humic acids for soil remediation

Fan Yang ${ }^{\mathrm{a}, \mathrm{b}^{*}}$, Shuaishuai Zhang ${ }^{\mathrm{a}}$, Kui Cheng $^{\mathrm{c}}$, Markus Antonietti ${ }^{\mathrm{b}}$

\begin{abstract}
Affiliations
a. School of Water Conservancy and Civil Engineering, Northeast Agricultural University, Harbin 150030, China

b. Max Planck Institute of Colloids and Interfaces Department of Colloid Chemistry 14476 Potsdam (Germany)

${ }^{c}$ Key Laboratory of Superlight Material and Surface Technology of Ministry of Education, College of Material Science and Chemical Engineering, Harbin Engineering University, Harbin 150001, China
\end{abstract}

Keywords: Simulated geochemistry; Artificial humic substances; Waste biomass; Hydrothermal process.

\begin{abstract}
A novel preparation protocol for synthetic, look-a-like humic substances (i.e., fulvic and humic acids) simulating geochemical processes through hydrothermal reaction is presented, with crude waste biomass as an omnipresent and universal precursor. The chemical nature of the organic scaffold and the type and abundance of oxygen-containing functional groups of the synthetic humic substances (A-FA and A-HA) are revealed by a series of examinations. Pyrolysis-gaschromatography/mass spectrometry (Py-GC/MS) analysis is employed on the organic structure and is directly compared to extracted natural humic matter from black soils (Harbin, China). Dehydrated carbohydrates and their condensates with low molecular weight that are rich in oxygen are the main structural components of the artificial fulvic acids, while aromatic structures and aliphatic side chains are almost absent. Aromatics $(7.43 \%)$ and in some cases long-chain aliphatics (7.15\%) are more prominent in the A-HA sample. The combination of the diverse analytical techniques not only allows a better understanding of artificial fulvic and humic acids, but also supports the high similarity to natural humic substances in structure and morphology. As the technology can be easily scaled and is comparable cheap, the as obtained products can be discussed to rehabilitate used up farm land.
\end{abstract}

\title{
1. Introduction
}

As a typical representative of the stable organic carbon pool in soil (Sollins, Homann, \& Caldwell, 1996), soil organic matter (SOM) accounts for up to $80 \%$ of the total organic matter in soil, thus playing a key role in soil fertility, but also the global carbon cycle (Shan, Brune, \& Ji, 2010). Soil organic matter contains more carbon than the combination of vegetation and the atmosphere and is a product of (endergonic) photosynthesis through land vegetation (Gortner, 1929; Wang et al., 2018). The direct product of photosynthesis are carbohydrates, but also lignin and alkyl tails play a key role in the more persistent parts of SOM. Photosynthesis immobilizes more than 220 billion metric tons of $\mathrm{CO}_{2}$ per year (Loomis, 1949), but only a small amount of this immobilized carbon ends up in SOM, as old plant matter is mostly metabolized and degraded, with 
little remainders via side reactions to form the soil carbon pool. The overall scale of easily available biomass (ca $10 \mathrm{Gt} /$ a waste biomass from industrial agriculture alone), in combination with an efficient process, however allows to speculate to use as generated humic matter as an effective tool for land rehabilitation or even terraforming, while dealing with the $\mathrm{CO}_{2}$ problem at the same time (Titirici, Thomas, Antonietti, 2007 ). Humic substances as the main constituents (up to 75\%) of SOM (Petrov, Tunega, Gerzabek, \& Oostenbrink, 2017) result from this biomass degradation through biological, physical and chemical transformation processes and are able to form complexes with soil minerals that can be stable up to timescales of thousands of years (Radwan et al., 1996). In addition, the previous literature has pointed out that humic substances promote plant growth and that metabolites of SOM can serve as phytohormones (Y. Chen \& Aviad, 1990). Most importantly, SOM and the complexes with inorganic minerals bind water, retain nutrients in soils and thereby make up land quality (Lal, 2004). Therefore, the addition of humic substances to weaker crop fields has gained popularity in agricultural practice due to the potential reduction of the necessity for irrigation and fertilizer.

The formation of humic substances under natural conditions requires quite a long time, involving biological and abiotic reactions, e.g., the decomposition to form humic substances found in the deep peat of papyrus and sphagnum (down to $20 \mathrm{~m}$ ) may last for up to 15000 years (Visser, 1962). Apparently, a "simple" extraction from natural rich soils for feeding back to the poor soils is practically impossible and conceptually meaningless. Agroindustry accomplishes the fabrication of humic acids and fulvic acids via chemical oxidation, fermentation and hydrolysis, but the tedious synthesis and demanding processing lead to comparably high costs.

Careful observation of natural processes can teach us some alternative approaches towards the formation of soil humic substances in black soils. Black soil is usually found in the North Temperate Zone with four distinct seasons and phases of rather humid soils resulting from sufficient annual rainfall (as shown in Fig. 1, a typical natural environment for black soil formation). In the black soil region, there is heat and abundant rainfall in the warm period, while the soil can be deeply frozen during the long winter, essentially retarding biological processes and promoting the role of chemistry. The soil microbial activity is therefore comparably weak, causing a slower metabolization of dead leaves and plant residues, thus resulting in a thick humus layer formed partly over thousands of years. Peatlands as carbon-rich ecosystems store one-third of the soil carbon but cover just three percent of the land surface of the earth (Dargie et al., 2017). Peatlands are found again mostly in moderate climatic regions, and the decomposition of organic matter under waterlogged anoxic conditions with low $\mathrm{pH}$ and low oxygen availability (Bordelet, Beaucaire, Phrommavanh, \& Descostes, 2018) is something that inspires chemical processing.

In addition, the biological, physical and chemical transformation processes to convert dead biomass into organic products must be seen in the frame of an intimate association with soil minerals to generate near neutral $\mathrm{pH}$ as an important characteristic of black soil. Obviously, the decomposition cascades in presence of minerals are "self-neutralizing", i.e., both rather acidic and alkaline starting products generate counter-products prompting their neutralization. In addition, published reports have pointed out that some soil invertebrates possess an alkaline intestinal digestion system that can degrade and mineralize otherwise stabilized components of humic compounds in soil (Ji, Kappler, \& Brune, 2000). Alkaline environments are favorable for dissociating the stabilized humic-mineral complexes and enhance the solubility of humic compounds (Kappler \& Brune, 1999).

Inspired by these facts, hydrothermal processing under autogenous pressure of still wet biomass under exclusion of oxygen can be considered a mild chemical process simulating natural 
coalification, but with an acceleration factor of up to $10^{9}$; in addition, as an abiotic process, hydrothermal processing usually achieves excellent carbon yields: the majority of the carbon bound in biomass ends up in the humified product. This progress is also very different from flame processes, where a major part of the biomass carbon is oxidized and released as greenhouse gases ( $\mathrm{CO}_{2}$ and $\left.\mathrm{CO}\right)$ (Andreae \& Merlet, 2001; Shi, Matsunaga, Saito, Yamaguchi, \& Chen, 2015). Avoiding metabolization by biological conversion schemes, but extending previous hydrothermal recipes to mimic the SOM formation, a previously unexpected process design with moderate energy input and high carbon yields is put forward. In the present work, artificial fulvic acid (AFA) and humic acid (A-HA) are successfully synthesized through one-step hydrothermal technology with crude biomass as precursors. Using the principle of "auto-neutralization" discussed above, we start with appropriately alkaline solutions creating exactly the corresponding amount of carboxylate groups in the then acidic covalent humic polymers. The structure and composition of as-prepared polymeric organic acids and phenols and relative formation mechanism are systematically discussed. While this work will stay with the characterization of artificial humic matter as such, the follow up work in this series will focus on the functional properties of A-SOM, i.e. will quantify the binding of water and nutrients in artificial soils, and will analyze the influence of the addition of A-SOM for promoting the microbial polytype.

\section{Materials and Methods}

Glucose (purity $>98.0 \%$ ) and potassium hydroxide $(\mathrm{KOH})$ (purity $>98.0 \%$ ) were purchased from Sigma-Aldrich. Various biomasses were collected in Potsdam, Germany. Typically, $1.20 \mathrm{~g}$ precursor powders and various masses of $\mathrm{KOH}$ were put into the bottom of the glass tube in $50 \mathrm{ml}$ autoclave, and the closed container was heated in the oven to $473 \mathrm{~K}$ for $24 \mathrm{~h}$. After the temperature naturally cooled down to room temperature, liquid products are obtained, named as G-2, W-2 and L-2. To obtain the pure organic acids, the resulting liquids are acidified with $6.0 \mathrm{~mol} / \mathrm{L} \mathrm{HCl}$ to $\mathrm{pH}$ 3 and then filtrated along with cleaning, drying and grinding. As a reference, the solid products prepared without $\mathrm{KOH}$ addition are also collected and examined, named as G-1, W-1 and L-1. The extraction of natural humic substances from black soil was similar to the procedure described in ref. (Shulga et al., 2017).

\section{Results}

The designed chemical pathway to make humic matter from carbohydrates and waste plant biomass is simple and here briefly explained. When "cooking" carbohydrates and their polymers in alkaline media, even polymeric carbohydrates are "digested" (i.e. turned into a liquid without residue). In this phase, sugars undergo retro-aldol addition and split into at least two organic acids (Esposito \& Antonietti, 2013), ideally into two lactic acid molecules (Huo et al., 2014). Analysis of real samples, however, indicates that a diverse multiplicity of hydroxyl- and ketoacids, including succinic acid, are obtained (Adam et al., 2015). That is, alkaline digestion essentially emulates microbial acidolysis (P. Chen, Tao, \& Zheng, 2016; Yang, Wang, Li, \& Lin, 2017). Each sugar molecule that way neutralizes at least two base units, i.e. the sugars are active species to auto-neutralize alkaline soils or ashes. In full lignocellulosic biomass, both cellulose and hemicellulose are digested along the same path, while the lignin component dissolves partly as phenolates in the water phase, while more hydrophobic lignin condensates remain undissolved.

Classical hydrothermal carbonization thereby, even when started under neutral conditions, quickly generates the same organic acids until a $\mathrm{pH}$ of approximately 5 is reached. At this $\mathrm{pH}$, retro-Aldol reaction seems to stop, and next, the polysaccharides first hydrolyze, but are then 
dehydrated into hydroxymethylfurfural ( $\mathrm{C}_{6}$-sugars) or furfural ( $\mathrm{C}_{5}$-sugars) (Titirici, Antonietti, \& Baccile, 2008), two monomers that quickly condense into a highly cross-linked carbonaceous material, called hydrochar (Demir-Cakan, Baccile, Antonietti, \& Titirici, 2009; Hu et al., 2010). To make linear or slightly branched humic polymers, it is now straightforward to combine the process of acidolysis (to generate the carboxylic groups with their ability to bind water) and condensation by $\mathrm{pH}$ programming throughout the reaction. When taking simply less than stoichiometric alkali (with the amount of base determining the acid functionality of the polymer), the $\mathrm{pH}$ in the reaction first drops to slightly acidic condensation, and condensation of the carbonaceous framework sets in, involving also a majority of the first formed organic acids and phenols. We name this refined version of the process "hydrothermal humification" (HTH).

This pathway was explored both with glucose as a model compound and two different crude biomass models, dried fruit stands from the tulip tree (Liriodendron tulipifera) and corewood sawdust of beech (Fagus sylvatica). The dried fruit stands come in $20 \mathrm{~kg} /$ tree, are rich in oils and waxes and constitute a hydrophobic biomass model, while sawdust is rather hydrophilic. Indeed, in all cases, a strongly brown liquid phase in coexistence with a water-swollen solid resin was obtained. The liquid phase could be completely precipitated at strongly acid $\mathrm{pH}$, showing fulvicand humic acid-like character. Photographs of these precipitated and dried samples are shown in Fig. $1 \mathrm{~b}$ and $1 \mathrm{c}$. Indeed, the glucose product is lower in molecular weight and more blackish, while the full biomass products contain aromatic compounds of the lignin, are brown and have a higher molecular weight. These characteristics are why we named the products "artificial fulvic acid" and "artificial humic acid", to be justified later by all other measurements.

Table $\mathrm{S} 1$ indicates that the reaction solution indeed underwent a large change in $\mathrm{pH}$ value from the starting strongly basic $(\mathrm{pH}=11.5)$ conditions to nearly neutral $(\mathrm{pH}=6.5-7.3)$ after the alkaline hydrothermal process. Interestingly, the as-formed brown liquids with suitable $\mathrm{pH}$ value have potential add-on applications as plant nutrients because neutralization has occurred between alkali $(\mathrm{KOH})$ and the as-formed organic acids during the synthetic progress, representing an organic ion binding structure with abundant potassium for plant growth. Notably, the liquid products in absence of $\mathrm{KOH}$ are weakly acidic $\mathrm{pH}(\sim 6.0)$, analogous to the formation of acidic peatlands under anaerobic conditions due to chemically aged biomass (Draper et al., 2014; Page, Rieley, \& Banks, 2011).

Quantitative yields of solid and liquid products obtained from the various biomasses with and without the addition of base (more details on yield calculation are shown in Supporting Information) exhibit marked differences ( $38.7 \%$ versus $0.08 \%$ for glucose, $78.4 \%$ versus $54.1 \%$ for wood powders and $73.0 \%$ versus $45.8 \%$ for tulip tree), indicating how much of the primary biomass became water soluble by carboxylation. Glucose $\left(\mathrm{C}_{6} \mathrm{H}_{12} \mathrm{O}_{6}\right)$ is a simple case that can easily be cut into smaller pieces under harsh basic conditions and then recombine with other fragments under the neutral conditions to form the final organic acids. Almost all educts are converted to dissolved acids (only $0.08 \%$ leftovers). Lignin on the other hand, as a typical aromatic polymer, has been suggested to essentially keep its initial structure under such mild conditions of hydrothermal carbonization (Carbonization, 2011; Wikberg, Ohra-aho, Pileidis, \& Titirici, 2015), and only reactive modification with activated monomers can take place. Therefore, tulip tree fruit stands and beechwoods result in higher SY and lower LY compared to the model glucose. Nevertheless, significant yields of soluble artificial humic acids relative to the crude biomass precursor are obtained. 


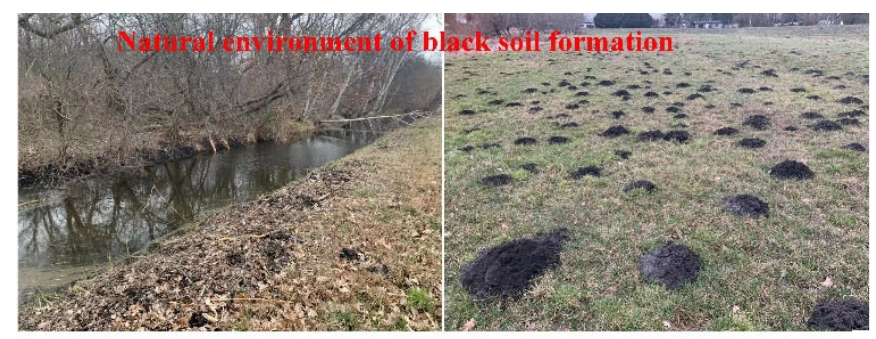

Formation of lignin

Chemical formation route of humic substances:
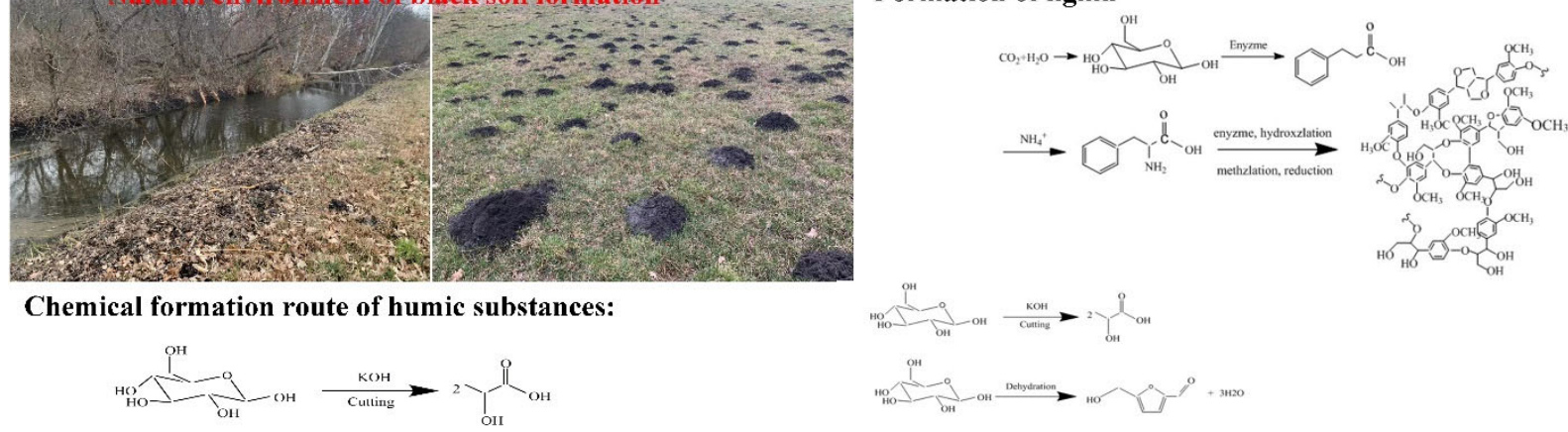

A-FA

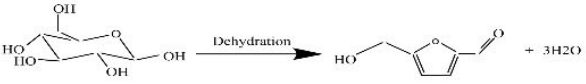

A-HA
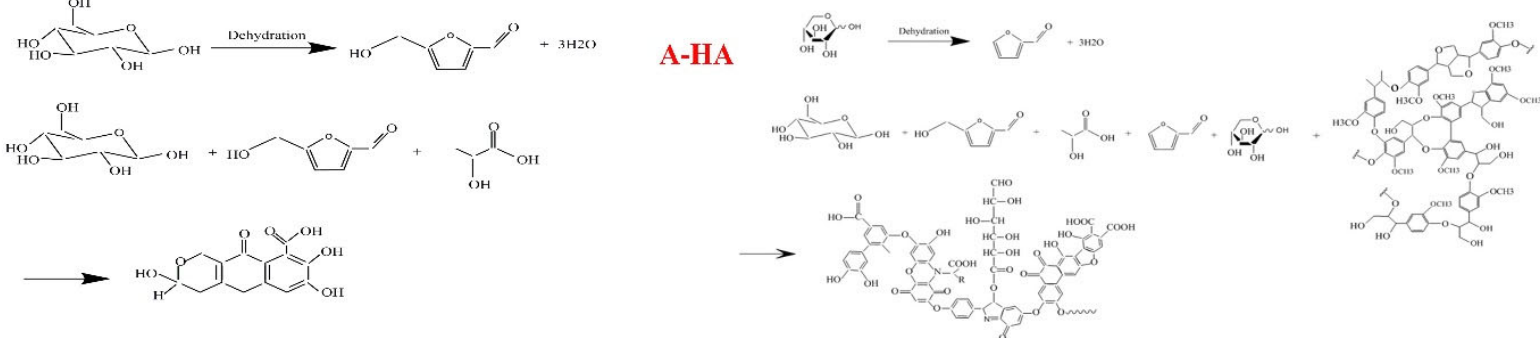

Fig. 1. The possible routes for the synthesis of lignin, artificial fulvic and humic acids and the pictures of natural environment of black soil formation.

A series of comparative SEM images are shown in Fig. S1-S4. They disclose further details of the action of alkali, here indirectly by the change in morphology. While under neutral conditions, we observed a tendency to form spherical hydrochar, after alkali addition the development of high surface area systems with abundant pores is observed (Long, Chen, Jiang, Zhi, \& Fan, 2015). This morphology speaks for the very polar group on the surface that prefer to stay exposed to the water phase for interface energy reasons. 
$\mathbf{a}$

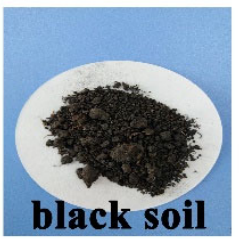

b

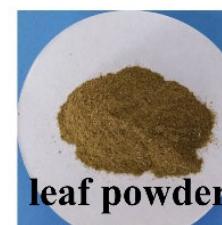

c

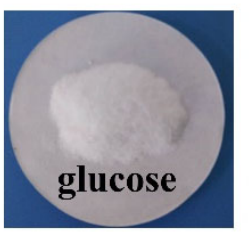

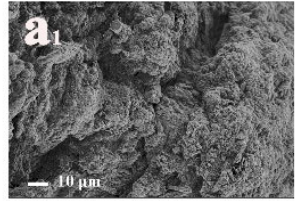
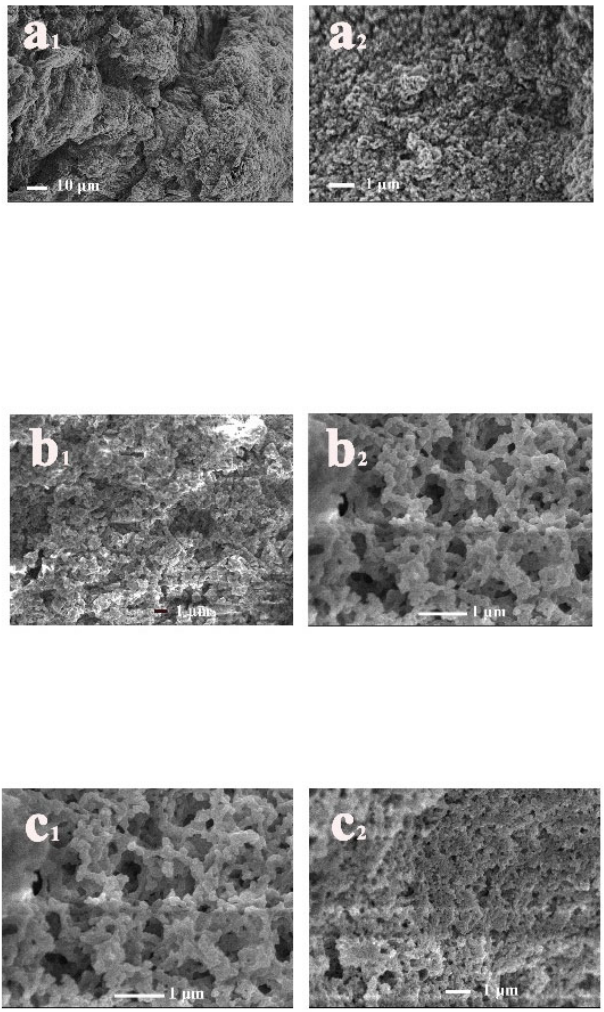

Fig. 2. Photographs and low- and high-magnification SEM images of natural humic acids extracted from black soil $\left(a_{1}\right.$ and $\left.a_{2}\right)$, artificial humic acids from leaves of tulip trees $\left(b_{1}\right.$ and $\left.b_{2}\right)$ and artificial fulvic acid from glucose $\left(c_{1}\right.$ and $\left.\mathrm{c}_{2}\right)$.

Low- and high-magnification SEM images are shown in Fig. 2, and only slight differences between A-FA and A-HA morphology after precipitation from the solution phase with strong acids can be observed, as the neutralization reveals the hydrophobic character of the humic backbones, leading to agglomerations of the chains (Terashima, Fukushima, \& Tanaka, 2004). The texture of these synthetic samples can be compared with natural humic substances extracted from black soil, and the similarities can be easily seen in Fig. 1a1 and a2.

Table S2 compares composition information. Obviously, A-HA samples show more carbon $(61.56 \%)$, hydrogen $(5.74 \%)$ and nitrogen $(1.03 \%)$ and less oxygen $(29.69 \%)$ than A-FA, suggesting a higher degree of humification (Xiaoli, Shimaoka, Qiang, \& Youcai, 2008). Notably, nitrogen and sulfur are not detected in the A-FA sample, consistent with the choice of a pure glucose precursor. For N-HA powders, the total amount of organic elements detected is around $97 \%$ rather than the nearly $100 \%$ in artificial samples, pointing to the presence of other mineralic soil elements (i.e., Si) also found in the corresponding EDX spectrum (Fig. S5). A higher nitrogen content (3.93\%) is found in N-HA, a result of a larger amount of proteins, DNA, and chlorophyll in the natural biomass (Sutton \& Sposito, 2005). Nitrogen moieties can maintain long-term stability against biodegradation (Verma, Martin, \& Haider, 1975), benefitting from formation of organo-mineral complexes, covalent incorporation into or physico-chemical encapsulation within phenolic moieties (Knicker \& Hatcher, 1997). 
Furthermore, the atomic ratios of $\mathrm{H} / \mathrm{C}, \mathrm{O} / \mathrm{C}$, and $\mathrm{C} / \mathrm{N}$ of humic substances are usually taken as important indicators of the degree of maturity and aromatic condensation (Steelink, 1985), so the calculated values of $\mathrm{H} / \mathrm{C}, \mathrm{O} / \mathrm{C}$, and $\mathrm{C} / \mathrm{N}$ in atomic ratios from the elemental analysis results are also given. Previous literature has described that the $\mathrm{H} / \mathrm{C}$ ratios increase with the increase in landfill age (Xiaoli et al., 2008). The $\mathrm{H} / \mathrm{C}$ ratio values are slightly higher than 1 , and this finding together with the decrease in the $\mathrm{O} / \mathrm{C}$ values for $\mathrm{A}-\mathrm{HA}$ and $\mathrm{N}-\mathrm{HA}$ samples indicates that an aromatic framework exists in the chemical structures of both humic acids. In addition, the $\mathrm{O} / \mathrm{C}$ ratio is considered a marker indicating how carbohydrate and carboxylic acids contribute to humic substances. Apparently, A-FA powders provide the highest $\mathrm{O} / \mathrm{C}$ ratio $(0.40)$ among the three samples, meaning that the as-prepared fulvic acids contained a high proportion of carboxylic acids and furans, very similar to descriptions of the natural FA samples (Weber \& Wilson, 1975). A-HA samples have an $\mathrm{O} / \mathrm{C}$ atom ratio of 0.36 , which is compared with 0.32 in $\mathrm{N}-\mathrm{HA}$. The $\mathrm{C} / \mathrm{N}$ ratio, commonly taken as an indicator of the sources of humic substances, reflects the original proportions of plant-derived material. The higher value of the $\mathrm{C} / \mathrm{N}$ ratio of $\mathrm{A}-\mathrm{HA}$ when compared to N-HA powders (69.70 versus 17.47$)$ reflects that we used land-sourced vascular plants as the dominant sources of artificial humic substances (Meyers \& Ishiwatari, 1993), while the lower C/N ratio of humic substances from black soil may be the reflection of microbial biomass entering the humification process, building on the abundant nitrogen-rich microorganisms in surface soil (Nelson, Dictor, \& Soulas, 1994). The classical concept of incorporation of microbial $\mathrm{N}$ in the humic fraction of soil organic matter has verified that resistant forms of $\mathrm{N}$ tend to remain throughout the humification process, causing a lower $\mathrm{C} / \mathrm{N}$ ratio (Almendros, Guadalix, GonzálezVila, \& Martin, 1996; Duchaufour \& Jacquin, 1975).

Table S3 lists the atom contents found at the surface of the A-FA, A-HA and N-HA samples determined by XPS analysis. The high carbon content (55.05 wt \% and $55.6 \mathrm{wt} \%$ ) of A-FA and A-HA quantifies their power for carbon sequestration. The elemental composition of artificial humic acids was set to match that of natural humic matter from black soils (Harbin, China). N-HA possesses higher $\mathrm{O}, \mathrm{N}$ and $\mathrm{S}$ contents and a lower $\mathrm{C}$ content, as discussed probably due to the incorporation of microbial proteins and DNA. Worth noting, N-HA had in the highest oxygen content and ratios of $\mathrm{O} / \mathrm{C}(1.28)$ and $(\mathrm{O}+\mathrm{N}) / \mathrm{C}(1.42)$ among the three samples. $\mathrm{N}$ content in N-HA sample is more than 3.56 times greater than that of in the sample A-HA, which fully agrees with the results from the EDX and EA analysis. Higher resolution XPS was conducted to further confirm the surface chemistry of the samples-A-FA, A-HA and N-HA, displayed in Fig. 3a. In the overview XPS spectrum of A-HA and N-HA samples, four peaks located at $168.3 \mathrm{eV}, 284.7 \mathrm{eV}$, $400.1 \mathrm{eV}$ and $532.6 \mathrm{eV}$ corresponded to $\mathrm{S} 2 \mathrm{p}, \mathrm{C} 1 \mathrm{~s}, \mathrm{~N}$ 1s and $\mathrm{O} 1 \mathrm{~s}$ (highlighted), respectively. Fig. $3\left(b_{1}-b_{2}\right)$ represent the high-resolution XPS spectra of C1s and O1s signals in A-FA sample. After deconvolution, $\mathrm{C} 1$ s peak can be decomposed into peaks located at 284.3, 284.8, 285.9 and 288.7 $\mathrm{eV}$, corresponding to $\mathrm{C}-\mathrm{C}(31.73 \%), \mathrm{C}-\mathrm{O}(44.85 \%), \mathrm{C}=\mathrm{O}(18.18 \%)$ and 

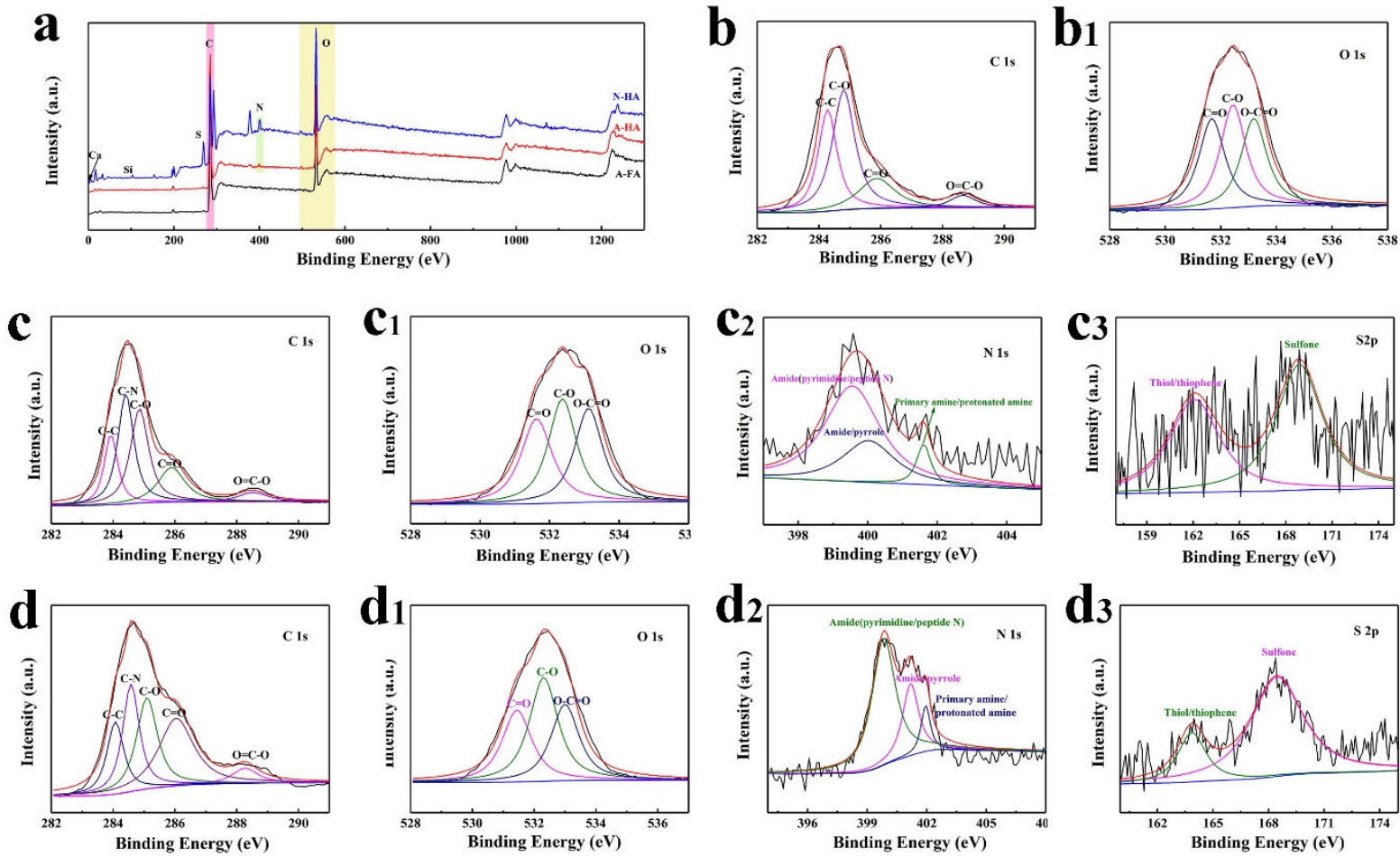

Fig. 3. XPS full survey of the artificial- and natural humic substances (a); High-resolution XPS scan of the C 1s (b1) and O 1s (b2) for A-FA sample; High-resolution XPS scan of the C 1s (c1), O 1s (c2), N 1s(c3) and S 2p (c4) for A-

HA sample; High-resolution XPS scan of the $\mathrm{C} 1 \mathrm{~s}(\mathrm{~d} 1), \mathrm{O} 1 \mathrm{~s}(\mathrm{~d} 2), \mathrm{N} 1 \mathrm{~s}(\mathrm{~d} 3)$ and $\mathrm{S} 2 \mathrm{p}(\mathrm{d} 4)$ for N-HA sample. $\mathrm{O}-\mathrm{C}=\mathrm{O}(5.24 \%)$. There are three types of oxygen species shown in $\mathrm{O} 1 \mathrm{~s}$ spectrum: $\mathrm{C}=\mathrm{O}(531.7 \mathrm{eV}$, $32.2 \%)$, $\mathrm{C}-\mathrm{O}(532.4 \mathrm{eV}, 36.4 \%)$ and $\mathrm{O}-\mathrm{C}=\mathrm{O}(533.2 \mathrm{eV}, 31.2 \%)$ (Zhu, Chen, Li, Yuan, \& Wang, 2017). The C1s spectra of the A-FA sample are quite different from the other two samples, pointing to the different structure of fulvic acids. N1s peak of A-HA was deconvoluted and positioned at respectively $399.6 \mathrm{eV}, 400.0 \mathrm{eV}$ and $401.6 \mathrm{eV}$, which can be assigned to amide (pyrimidine/peptide N), amide/pyrrole and primary amine/protonated amine, and possible connected to other structures such as methylpyrrole, indole and amino acid dimers (Fig. $3 \mathrm{c}_{2}$ ). Amides are more characteristic of N-HA than the A-HA, again pointing to protein leftovers (Doskočil, Burdíková-Szewieczková, Enev, Kalina, \& Wasserbauer, 2018) (Fig. 3d2). In highresolution XPS spectra of S 2p in A-HA samples could be deconvoluted into peaks at $168.5 \mathrm{eV}$ (thiol/thiophene) and $163.9 \mathrm{eV}$ (sulfone) (Fig. 3 $\mathrm{c}_{3}$ ), which is also detected by means of Py-GC/MS analysis (as discussed later). The above results show that the studied artificial and natural humic substances have a very similar chemical composition, with the differences being explained by the different microbial content.

Artificial and natural humic substances gave also similar FTIR spectra; a systematic comparison is given in Fig. 4a. The broad absorption band at $3330-3400 \mathrm{~cm}^{-1}$ is caused by the stretching vibrations of the $-\mathrm{OH}$ groups. A peak located at $1690-1720 \mathrm{~cm}^{-1}$ may result from the stretching vibrations of $\mathrm{C}=\mathrm{O}$ bonds of $-\mathrm{COOH}$ and ketones. Obviously, the peak intensities in AFA are stronger than in the A-HA sample, indicating abundant Saccharide acidolysis products and their derivatives. The peaks in the range of $2800-3000 \mathrm{~cm}^{-1}$ in A-FA shows a significant difference to those in A-HA and N-HA samples, reflecting the aliphatic stretching vibrations of $-\mathrm{CH}_{3}$ and $\mathrm{CH}_{2}$. Three bands in the range from 1230 to $1030 \mathrm{~cm}^{-1}$ together with the peaks at 662 and $830-860$ 
$\mathrm{cm}^{-1}$ can be attributed to the $\mathrm{C}-\mathrm{O}$ stretching of the $-\mathrm{COOH}$ groups and $\mathrm{C}-\mathrm{H}$ bending. Notably, a discriminative peak centered at $1520-1510 \mathrm{~cm}^{-1}$ is observed in both the curves of artificial and natural humic acids, but not for fulvic acids, resulting from stretching vibrations of - $\mathrm{NH}$ in amides (Crespilho et al., 2005; Schwartz \& Asfeld, 1963). The natural extract has stronger peaks at 1606 $\mathrm{cm}^{-1}$ and weaker bands at $1720 \mathrm{~cm}^{-1}$, suggesting more aromatic and fewer carboxyl structures. Additionally, higher peak intensity at $1210 \mathrm{~cm}^{-1}$ in the A-FA profile reflects the higher content of oxygen-containing functional groups, matching with a high oxygen content obtained from EA analysis. 

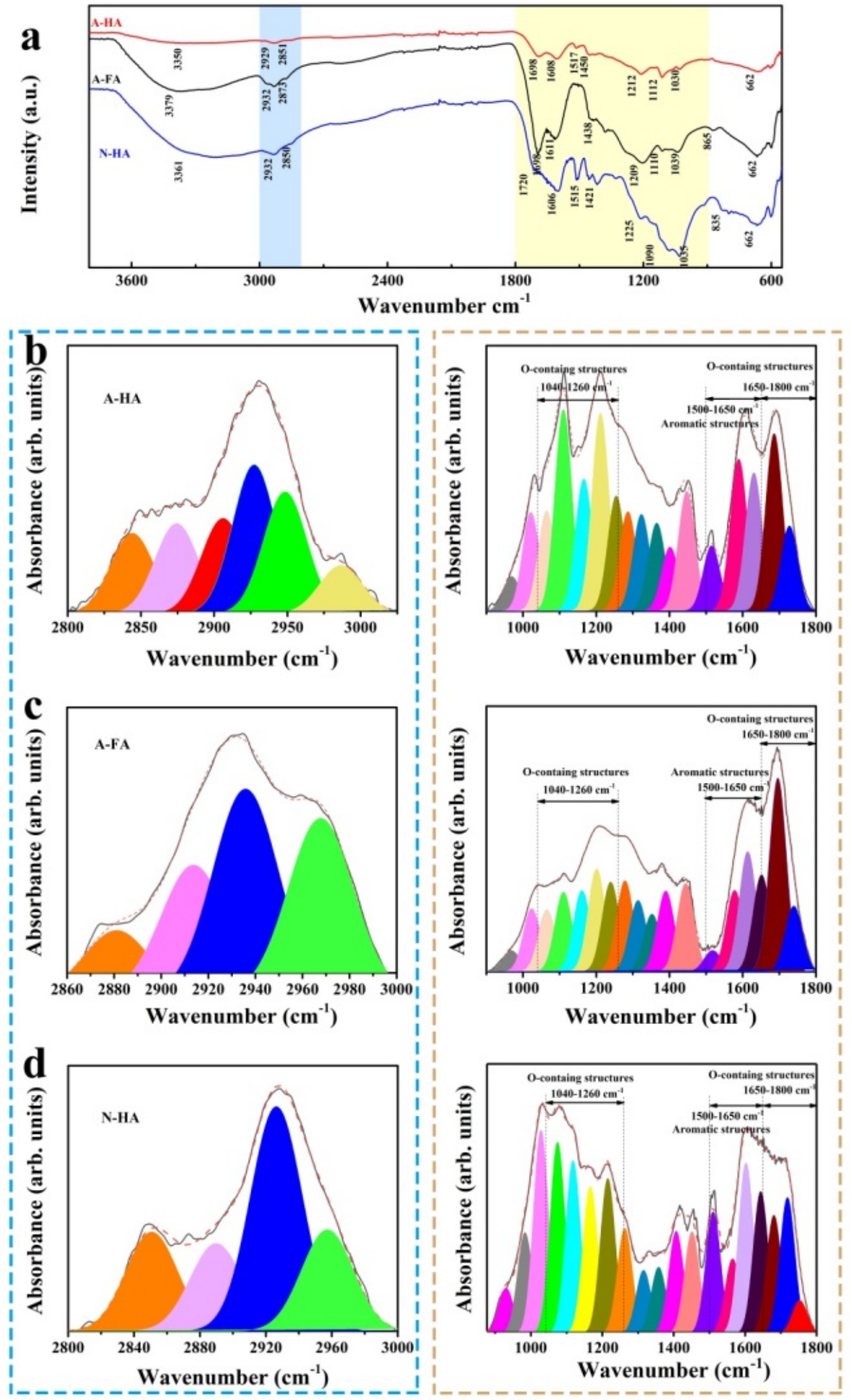

Fig. 4. FTIR spectrum of A-FA, A-HA and N-HA samples. 
To examine the changes in different functional groups of humic substances, peak-fitting results in two representative regions (highlighted in Fig. 4a) for semiquantitative analysis are presented in Fig. 4b-d. In the range of $2800-3000 \mathrm{~cm}^{-1}$ representing the aliphatic structure, relative peak areas in two bands at $\sim 2925$ and $\sim 2950 \mathrm{~cm}^{-1}$ attributed to asymmetric $-\mathrm{CH}_{2}$ and $-\mathrm{CH}_{3}$ estimate the length of the aliphatic chains and their degree of branching ( $\mathrm{Li} \& \mathrm{Zhu}, 2014)$. The area ratios in A-HA and N-HA are 1.22 and 2.21, meaning that natural humic substances have a longer length in aliphatic chains and lower structural saturation degree than the artificial samples, again speaking for a higher lipid content of the starting matter. FTIR spectra of A-FA in this range can be divided into four peaks at $2881.1,2913.7,2935.8$ and $2967.8 \mathrm{~cm}^{-1}$, and indicate the presence of C-H, blocks, created by hydride shift as in the generation of lactic acid. Furthermore, the area ratio of $\mathrm{A} 1800-1650$ ( $\mathrm{C}=\mathrm{O}$ in aromatics) to $\mathrm{A} \sim 1510(\mathrm{C}=\mathrm{C}$ in aromatics) (" $\mathrm{A}$ " representing "Area") in the range of $1800-900 \mathrm{~cm}^{-1}$ reflect the degree of humification, so the relative results are $16.73,4.02$ and 2.36 for A-FA, A-HA and N-HA, respectively, indicating an increase in humification level. Notably, similar values are found in artificial and natural humic acids while very weak peak intensity (1515 $\mathrm{cm}^{-1}$ ) corresponds to aromatic $\mathrm{C}=\mathrm{C}$ bonds in A-FA samples. We also compared the ratios of $\mathrm{A}_{1260}$ 1040 (C-O-R) to A1510, and they follow the order of A-FA (15.68)>A-HA (9.89)>N-HA (5.47),

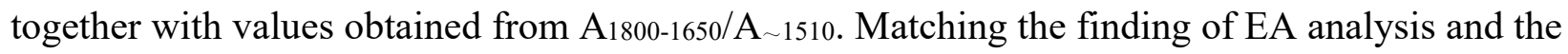
color of the sample, this suggests the existence on abundant aromatic frameworks in the chemical structures of both humic acids.
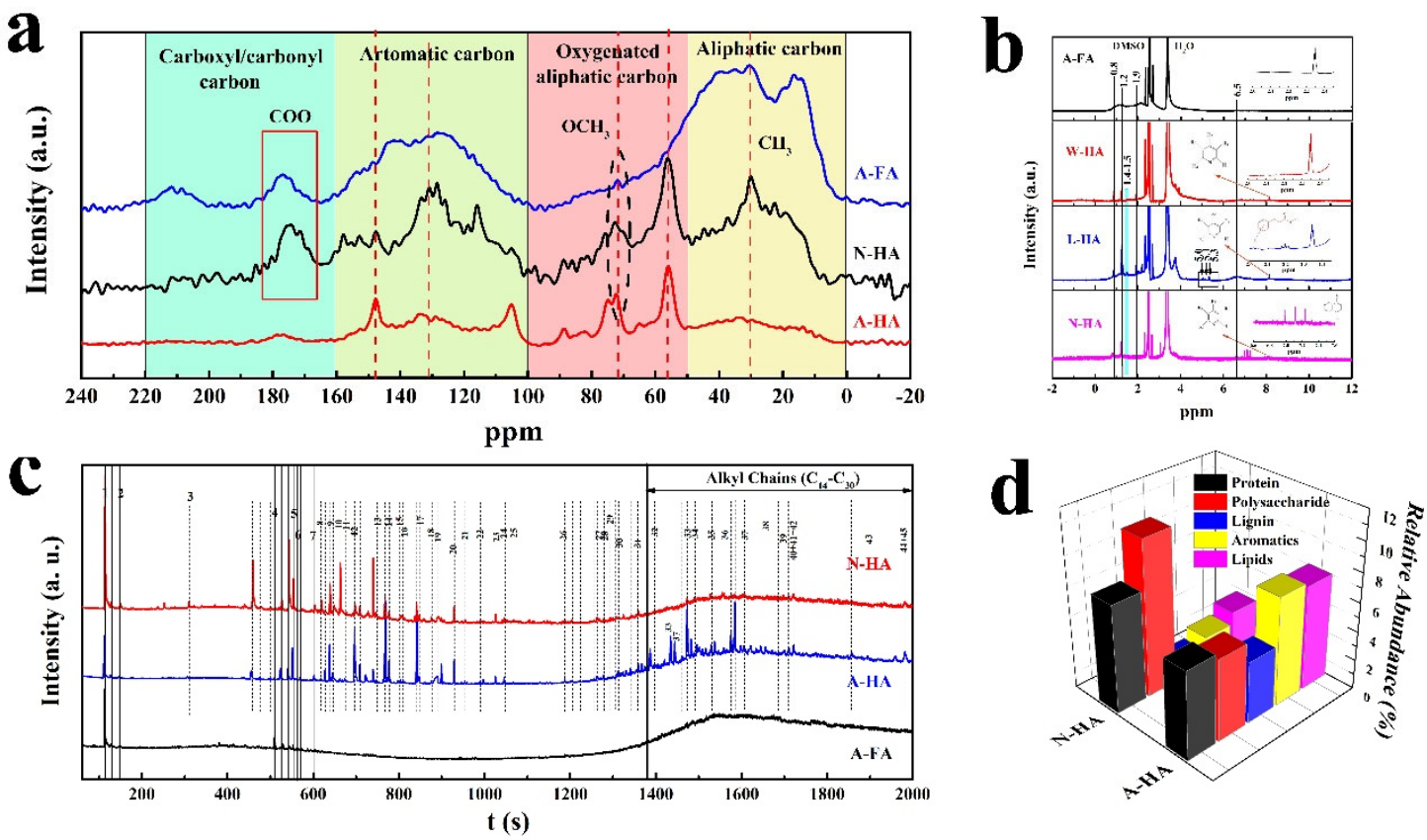

Fig. 5. (a) Solid state ${ }^{13} \mathrm{C}-\mathrm{NMR}$ spectra from artificial and natural humic substances; (b) Liquid state ${ }^{1} \mathrm{H}-\mathrm{NMR}$ spectra of A-FA derived from glucose, A-HA derived from corewood powders and tulip tree fruit stands, and natural humic acid extracted from black soil; (c) Chromatographic patterns obtained by the pyrolysis of comparative curves of natural-, artificial humic acid and artificial fulvic acid; (d) Relative abundance of compounds of N-containing, lignin-derived, cabohydrate-derived and aliphatics in the pyrograms of A-HA and N-HA samples; 
Nuclear magnetic resonance (NMR) spectroscopy is known as a useful tool for assessing the structural features of SOM, especially for humic substances (Lu, Hanna, \& Johnson, 2000; SáizJiménez \& De Leeuw, 1986). Fig. 5a presents solid state ${ }^{13} \mathrm{C}-\mathrm{NMR}$ spectra; the areas of major spectral bands with various relative intensities of every sample obtained by integration are listed in Table S4. The data are in good agreement with other observations of humics (Cao \& SchmidtRohr, 2018; Xiaoli et al., 2008). The spectra can be generally divided into four chemical regions, that is, aliphatic carbons (0-50 ppm), oxygenated aliphatic carbons (50-100 ppm), aromatic carbons (100-160 ppm), and carboxyl/carbonyl carbons (160-220 ppm) (Xiaoli et al., 2008). As observed in aliphatic carbon region, a prominent peak centered at $30 \mathrm{ppm}$ and a series of tiny signals is due to the presence of aliphatic - $\mathrm{CH}$, bound in structures of methyl, methylene, and methine groups, respectively. The higher abundance of long-chain fatty acids in N-HA sample causes higher intensities of peaks in N-HA pattern. A sharp signal located at $56 \mathrm{ppm}$ in A-HA and $\mathrm{N}-\mathrm{HA}$ spectrum can be assigned to $-\mathrm{OCH}_{3}$ aromatic methoxy groups. In contrast, only a tiny peak is found at the same location in A-FA spectra, owing to the lack of aromatic structures. in good agreement with FTIR results. At the same time, a relatively high intensity in the O-alkyl region (72 ppm) is caused by a high number of semicondensed carbohydrate structures in A-FA. Another difference among HA and FA samples occurs in the region of aromatic carbon, and two obvious peaks located at $130 \mathrm{ppm}$ (aromatic and unsaturated carbons) and $150 \mathrm{ppm}$ (phenols and heterocyclic aromatics) in combination with the prominent methoxy signal (56 ppm) indicate that lignin is the predominant aromatic structure in both the A-HA and N-HA spectra. In the carboxylic/carbonyl carbons region, the peaks at around $170 \mathrm{ppm}$ of N-HA and A-FA samples are much higher than that of A-HA, because of a high content of carboxylic groups.

Fig. $5 b$ is liquid state ${ }^{1} \mathrm{H}-\mathrm{NMR}$ spectra of humic substances. All NMR spectra show sharp highly resolved peaks ( $\delta 3.37$ and $\delta 2.52$ ) around the broad resonance of water, result from the hygroscopic DMSO, serving as common solvent for (wet) humic substance dissolution. Three clear peaks centered at $0.84,1.23$ and $1.94 \mathrm{ppm}$ ahead of the strong solvent DMSO peak $(\delta 2.52)$ indicate the existence of some small organic acids, e.g., methoxyacetic acid and 2-hydroxy-3methylbutyric acid (Cook, McIntyre, Langford, \& Vogel, 2003), originating from the alkaline splitting of glucose for A-FA preparation. NMR spectra of a series of humic acid samples have similar peaks, that is all samples contain aliphatic protons in the 0.5-2.3 ppm region (Francioso, Sanchez-Cortes, Tugnoli, Marzadori, \& Ciavatta, 2001), and small resonances at approximately 1.4-1.5 may be attributed to either $\beta$-methyl protons in alcohols such as $\mathrm{CH}_{3} \mathrm{CR}_{1} \mathrm{R}_{2} \mathrm{OH}$ or $\beta$ methylenic protons in amines such as $\mathrm{RCH}_{2} \mathrm{CH}_{2} \mathrm{NR}_{1} \mathrm{R}_{2}$ (Duddeck, Dietrich, \& Tóth, 2013). It can be concluded that the stronger intensities of signals at $1.23 \mathrm{ppm}$ in HA powders than in FA result from both wax and lignin content in the raw biomass (Wilson). Compared to the other NMR spectra representing humic acids, the low peak intensities and lack of peaks in range of 1.94-2.36 ppm on the W-HA plane revealed that lipids with a long aliphatic chain and paraffinic materials are less common in plant biomass precursors (as compared to microbial sludges). Conversely, LHA sample exhibit the nature of abundance in aliphatic compounds, and two peaks with triplets at 2.05 and $2.20 \mathrm{ppm}$ (better identified in the enlarged view in the insert of Fig. 5b) can be attributed to methylenic protons in benzylic units $(2.20 \mathrm{ppm})$ and $\alpha$-methylenic protons of carboxylic acid $(2.05 \mathrm{ppm})$ (structure as shown in insert). ${ }^{1} \mathrm{H}-\mathrm{NMR}$ absorptions in the following range of 4.2-6.6 ppm are attributed to olefinic compounds, and the range of $6.9-8.6 \mathrm{ppm}$ is attributed to aromatic and heterocyclic components. Three peaks located at 6.98, 7.11 and 7.24 ppm are typical for allcarbon, aromatic structures (shown in insert), while the one at $8.25 \mathrm{ppm}$ can be unequivocally 
assigned to a proton in highly substituted heterocyclic systems, and they are found in all three humic acids (structure as shown in insert).

These structural investigations of humic substances can be further complemented by PyGCMS, detecting their degradation products at high temperatures (Abbt-Braun, Frimmel, \& Schulten, 1989; Nagar, 1963) The here presented "fingerprint plots" show astonishing similarities ( Fig. 5c), and typical products are summarized in Table S5. Generally, we can attribute the peaks to four categories, namely, protein- (Pr), polysaccharide- (Ps), lignin- (Lg) and lipid-based (Lp) peaks. This allows a more detailed recognition of main pyrolysis fragments. Humic substances both from artificial process or natural extraction have more rich pyrolysis products with more than 40 major labeled peaks assigned to identified compounds, and most of them are in excellent correspondence to pyrolysis studies on humic substances reported before (Lu et al., 2000; SáizJiménez \& De Leeuw, 1986). The chemical diversity of humics is obviously by far greater than the chemical diversity of fulvic acid. The fact that almost all the characteristic peaks of humanmade humic acid correspond to the natural samples confirms our unique reaction design inspired by Nature, and only differences in the relative abundances are found. Thin confirms that humic substances derived from different sources in different formation environments are very similar, but different in relative composition and ternary compounds coming from the starting products. The "chemical-only" reaction towards artificial humic substances simulating geochemistry with hydrothermal conditions can indeed be considered as good, but more efficient in mimicking the complex chemical and biological degradation leading to the formation of natural humic substances.

Some representative fragments such as pyrrole, pyridine, and other N-containing compounds $(\mathrm{N}=8,9,10,11,17,18,35,36,38,41,42)$ are also detected in A-HA and N-HA samples, indicating the existence of proteinaceous constituents in the starting biomasses. Pyrrole and derivatives have a relatively higher signal than other $\mathrm{N}$-containing compounds in both curves, and the natural extraction product has a relatively larger abundance of $\mathrm{N}$-containing compounds released in the pyrograms shown in Fig. 5d (5.96\% in A-HA versus $7.34 \%$ in N-HA). Again, this is in good agreement with the elemental analysis results listed in Table S2 (3.93\% for N-HA and 1.03\% for A-HA). Not surprisingly, with glucose as the exclusive precursor for fabrication of artificial fulvic acid, no N-containing compounds can be found.

Guaiacol and its derivatives assigned to the peak number 29, 34, 39, 43 and 45 are the main fragments of lignin, and the weak signals of these compounds in pyrolysis products of all humic substances indicate that the pyrolysis temperature $\left(600{ }^{\circ} \mathrm{C}\right)$ is not favorable to isolate those products (Sihombing, Greenwood, Wilson, \& Hanna, 1996). Lignin units have frequently been detected in humic matter extracted from coal, peat and soil and are considered a source indicator of a terrestrial plant base (Marshall \& Page, 1927). The obvious increase in abundance of ligninderived fragments in artificial humic substances when compared to natural samples $(4.19 \%$ versus $1.23 \%$ ), implies that plant residues were the main contribution to formation of synthetic humic substances. Other aromatic compounds, i.e., ethylbenzene, toluene, ethylphenol and $m$ - and/or $p$ xylene are are also found in the pyrolysis products of proteins and polycarboxylic acids (Bracewell, Robertson, \& Williams, 1980), while their substantial abundances in the two humic acid samples (7.43\% in A-HA and $1.99 \%$ in N-HA) indicates lignin-derived subunits as the main source. For A-FA powders, almost no pyrolysis fragments attributed to lignin units are found, while some trace peaks match with pyrolysis products from polysaccharides (i.e., acetone, dimethylfuran, vinylfuran, overall 6.27\%) (Xiaoli et al., 2008). In addition, the large amounts of furan and derivatives $(5.55 \%)$ in the pyrolysis products further confirm the predominant carbohydrate origin of the artificial fulvic acid. 
A significant proportion of long-chain fatty acids was detected in the products of both A-HA (tulip tree) and N-HA, and the main aliphatic compounds identified are nonene, octene, undecene and tetracosanol, methyldecane-1,10-dioate and other long-chain fatty acid methyl esters. These peaks come from lipids as residues from microbial activity but also waxes and fats in skin and the sealing layers of plants, and their relative abundances in hydrophobic A-HA are larger than their relative abundances in N-HA $(7.15 \%$ versus $2.80 \%)$. Compared to both humic acids, artificial fulvic acids contain almost no aliphatics, consistent with all other results. The fatty acids have been found to be bound to HA through esterification with hydroxyl groups, allowing them to form intermolecular hydrophobic pockets between the aromatic building blocks of humic substances (Xiaoli et al., 2008).

\section{Mechanism}

Decomposition of animal and plant residues, microorganisms and deuterogenic organic substances are the dominant sources of soil humic substances. In particular, plants provide the largest contribution to the structure and composition of soil humic matter. Plants mainly consist of structural polysaccharides and lignin, together with minor amounts of lipids and proteinaceous materials. This work has focused on a realistic simulation of the humification process under accelerated conditions for delivering artificial SOM for practical application. Therefore, glucose, as a typical monomer of natural polysaccharides, is chosen as a model compound to generate AFA, based on the fact that natural fulvic acids are commonly water-soluble, relatively lowmolecular-weight humic materials with few aromatic structures (Schnitzer, 1969). Previous work has pointed out that glucose can be effectively converted into lactic acids with alkaline catalysts $\left(\mathrm{C}_{6} \mathrm{H}_{12} \mathrm{O}_{6} \rightarrow 2 \mathrm{C}_{3} \mathrm{H}_{6} \mathrm{O}_{3}\right)$ (Huo et al., 2014; Yan, Jin, Tohji, Kishita, \& Enomoto, 2010). At the same time, glucose under slightly acidic conditions is dehydrated to form 5-hydroxymethyl-furfural-1aldehyde (HMF), as published previously (Lourvanij \& Rorrer, 1993; Titirici et al., 2008). In an appropriate $\mathrm{pH}$-programmed reaction, the as-formed hydroxyl acids and HMF may recombine and undergo further polycondensation. A plausible scheme for fulvic acid preparation from glucose in basic solution under hydrothermal conditions complying with all structural data is presented in insert of Fig. 1. Natural fulvic acid molecules have remained nebulous to date, so the diagram depicts only a possible structure according to the comprehensive characterizations (Stevenson, Fitch, \& Brar, 1993).

For real lignocellulosic biomass, cellulose, hemicellulose and lignin are the main ingredients contained in plants, and lignin can be considered to change only slightly during the process (Wikberg et al., 2015) at "mild" temperatures of $200^{\circ} \mathrm{C}$ as applied in this paper, but of course can condense into a forming network structure as building blocks. The insert of Fig. 1 also illustrates schematically a chemical reaction cascade during the preparation of humic acids from crude biomass based on a few assumptions. Obviously, multiple reactions among a certain number of small molecules including glucose, xylose and their typical derivatives (lactic acid, HMF and furfural) together with the remaining lignin structure may proceed through auto-polycondensation and recombination. In addition, a certain number of fatty acids $(7.15 \%)$ detected in the hydrophobic A-HA sample coming from the wax and lipid constituents of the crude biomass are built in as side chains and increase the hydrophobic character of the artificial SOM, contributing

to its binding properties for a variety of important compounds such as phytohormones and metabolites.

\section{Conclusions}

In this paper, we present a simple and convenient process for the production of artificial fulvic acid from glucose and humic acids from two waste biomasses under moderate alkaline 
hydrothermal conditions, mimicking but accelerating the natural humification progress. The results demonstrated that $\mathrm{C}, \mathrm{H}$ and $\mathrm{O}$ are forming a covalent structure, with acidic groups being the main, name-giving functionality. Pyrolysis-GC/MS applied as a "fingerprinting technique" shows astonishing similarity between the two synthetic and one natural (extracted) humic acid samples, with the synthetic samples only slightly less diverse in fragments than the natural sample. In our opinion, these abundances reflect the more homogeneous nature of the synthetic starting products and a significant microbial contribution to the biomass pool in the natural humic acids. The present work already indicates high relevance of the synthesized materials for practical applications, e.g., the production of humic substances to remediate used-up land. Experiments on a more refined structural analysis of artificial humus compared with real humic substances of different origin are also under way.

\section{Supporting Information}

Fig. S1. Low- and high-magnification SEM images of solid residues derived from glucose via hydrothermal reaction in absence of KOH; Fig. S2. Low- and high-magnification SEM images of solid residues derived from glucose via hydrothermal reaction in presence of $\mathrm{KOH}$; Fig. S3. Lowand high-magnification SEM images of solid residues derived from wood powders via hydrothermal reaction in absence (a, b) and presence of $\mathrm{KOH}(\mathrm{c}, \mathrm{d})$; Fig. S4. Low- and highmagnification SEM images of solid residues derived from eucalyptus leaves via hydrothermal reaction in absence (a, b) and presence (c, d) of KOH; Fig. S5. The corresponding EDX spectrum of natural humic acids Table S1. Yields of solid and liquid products obtained from glucose and crude biomass; Table S2. Comparative results obtained from elemental composition analysis and atomic rations of artificial and natural humic substances; Table. S3. Atom contents of the surface of the A-FA, A-HA and N-HA samples; Table. S4. The percent of aliphaticity and aromaticity of artificial- and natural humic substances; Table S5. Typical products and relative peak area of artificial and natural humic substances identified by Py-GC/MS analysis. (Pr=Protein; Ps=polysaccharide; $\mathrm{Lg}=$ Lignin; Lp=Lipids).

\section{Corresponding Author}

*Corresponding author: Antonietti@mpikg.mpg.de; in equal parts yangfan_neau@163.com

\section{Author Contributions}

The manuscript was written through contributions of all authors. All authors have given approval to the final version of the manuscript. $\ddagger$ These authors contributed equally. (match statement to author names with a symbol)

\section{Acknowledgement}

All authors appreciate the funding of the project by Max Planck Society. Dr. Yang acknowledges the financial support from the National Natural Science Fund for Young Scholars (31600413), the financial support from University Nursing Program for Young Scholars with Creative Talents in Heilongjiang Province (UNPYSCT-2017018), Natural Science Foundation of Heilongjiang Province of China (QC2018019). 


\section{Abbreviations}

A-FA, artificial fulvic acid; A-HA, artificial humic acid; N-HA, natural humic acids extracted from black soil; SOM, soil organic matter; HTH, hydrothermal humification; SY, solid yield; LY, liquid yield; W-HA, artificial humic acid from corewood sawdust of beech; L-HA, artificial humic acid from tulip trees.

\section{References}

Abbt-Braun, G., Frimmel, F. H., \& Schulten, H.-R. (1989). Structural investigations of aquatic humic substances by pyrolysis-field ionization mass spectrometry and pyrolysis-gas chromatography/mass spectrometry. Water Research, 23(12), 1579-1591. doi:https://doi.org/10.1016/0043-1354(89)90124-3

Adam, Y. S., Fang, Y., Huo, Z., Zeng, X., Jing, Z., \& Jin, F. (2015). Production of carboxylic acids from glucose with metal oxides under hydrothermal conditions. Research on Chemical Intermediates, 41(5), 3201-3211. doi:10.1007/s11164-013-1425-4

Almendros, G., Guadalix, M. E., González-Vila, F. J., \& Martin, F. (1996). Preservation of aliphatic macromolecules in soil humins. Organic geochemistry, 24(6-7), 651-659.

Andreae, M. O., \& Merlet, P. (2001). Emission of trace gases and aerosols from biomass burning. Global biogeochemical cycles, 15(4), 955-966.

Bordelet, G., Beaucaire, C., Phrommavanh, V., \& Descostes, M. (2018). Chemical reactivity of natural peat towards $\mathrm{U}$ and Ra. Chemosphere, 202, 651-660. doi:https://doi.org/10.1016/j.chemosphere.2018.03.140

Bracewell, J.-M., Robertson, G., \& Williams, B. (1980). Pyrolysis - mass spectrometry studies of humification in a peat and a peaty podzol. Journal of Analytical and Applied Pyrolysis, 2(1), 53-62.

Cao, X., \& Schmidt-Rohr, K. (2018). Abundant Nonprotonated Aromatic and Oxygen-Bonded Carbons Make Humic Substances Distinct from Biopolymers. Environmental Science \& Technology Letters.

Carbonization, H. (2011). 1. Influence of Lignin in Lignocelluloses Dinjus, E.; Kruse, A.; Troeger, N. Chemical Engineering \& Technology, 34(12), 2037-2043.

Chen, P., Tao, S., \& Zheng, P. (2016). Efficient and repeated production of succinic acid by turning sugarcane bagasse into sugar and support. Bioresource Technology, 211, 406-413. doi:https://doi.org/10.1016/j.biortech.2016.03.108

Chen, Y., \& Aviad, T. (1990). Effects of humic substances on plant growth 1. Humic substances in soil and crop sciences: Selected readings(humicsubstances), 161-186.

Cook, R. L., McIntyre, D. D., Langford, C. H., \& Vogel, H. J. (2003). A comprehensive liquidstate heteronuclear and multidimensional NMR study of Laurentian fulvic acid. Environmental Science \& Technology, 37(17), 3935-3944.

Crespilho, F. N., Zucolotto, V., Siqueira, J. R., Constantino, C. J. L., Nart, F. C., \& Oliveira, O. N. (2005). Immobilization of Humic Acid in Nanostructured Layer-by-Layer Films for Sensing Applications. Environmental Science \& Technology, 39(14), 5385-5389. doi:10.1021/es050552n

Dargie, G. C., Lewis, S. L., Lawson, I. T., Mitchard, E. T. A., Page, S. E., Bocko, Y. E., \& Ifo, S. A. (2017). Age, extent and carbon storage of the central Congo Basin peatland complex. Nature, 542, 86. doi:10.1038/nature21048

https:/www.nature.com/articles/nature21048\#supplementary-information 
Demir-Cakan, R., Baccile, N., Antonietti, M., \& Titirici, M.-M. (2009). Carboxylate-rich carbonaceous materials via one-step hydrothermal carbonization of glucose in the presence of acrylic acid. Chemistry of materials, 21(3), 484-490.

Doskočil, L., Burdíková-Szewieczková, J., Enev, V., Kalina, L., \& Wasserbauer, J. (2018). Spectral characterization and comparison of humic acids isolated from some European lignites. Fuel, 213, 123-132.

Draper, F. C., Roucoux, K. H., Lawson, I. T., Mitchard, E. T., Coronado, E. N. H., Lähteenoja, O., ... Baker, T. R. (2014). The distribution and amount of carbon in the largest peatland complex in Amazonia. Environmental Research Letters, 9(12), 124017.

Duchaufour, P., \& Jacquin, F. (1975). Comparaison des processus d'humification dans les principaux types d'humus forestiers. Bull. AFES, 1, 29-36.

Duddeck, H., Dietrich, W., \& Tóth, G. (2013). Structure elucidation by modern NMR: a workbook: Springer Science \& Business Media.

Esposito, D., \& Antonietti, M. (2013). Chemical conversion of sugars to lactic acid by alkaline hydrothermal processes. ChemSusChem, 6(6), 989-992.

Francioso, O., Sanchez-Cortes, S., Tugnoli, V., Marzadori, C., \& Ciavatta, C. (2001). Spectroscopic study (DRIFT, SERS and 1H NMR) of peat, leonardite and lignite humic substances. Journal of molecular structure, 565, 481-485.

Gortner, R. (1929). Outlines of Biochemistry John Wiley and Sons. Inc., New York, N. Y.

Hu, B., Wang, K., Wu, L., Yu, S. H., Antonietti, M., \& Titirici, M. M. (2010). Engineering carbon materials from the hydrothermal carbonization process of biomass. Advanced Materials, 22(7), 813-828.

Huo, Z., Fang, Y., Ren, D., Zhang, S., Yao, G., Zeng, X., \& Jin, F. (2014). Selective conversion of glucose into lactic acid with transition metal ions in diluted aqueous $\mathrm{NaOH}$ solution. ACS Sustainable Chemistry \& Engineering, 2(12), 2765-2771.

Ji, R., Kappler, A., \& Brune, A. (2000). Transformation and mineralization of synthetic 14Clabeled humic model compounds by soil-feeding termites. Soil Biology and Biochemistry, 32(8-9), 1281-1291.

Kappler, A., \& Brune, A. (1999). Influence of gut alkalinity and oxygen status on mobilization and size-class distribution of humic acids in the hindgut of soil-feeding termites. Applied Soil Ecology, 13(3), 219-229.

Knicker, H., \& Hatcher, P. G. (1997). Survival of protein in an organic-rich sediment: possible protection by encapsulation in organic matter. Naturwissenschaften, 84(6), 231-234.

Lal, R. (2004). Soil carbon sequestration impacts on global climate change and food security. Science, 304(5677), 1623-1627.

Li, W., \& Zhu, Y. (2014). Structural Characteristics of Coal Vitrinite during Pyrolysis. Energy \& Fuels, 28(6), 3645-3654. doi:10.1021/ef500300r

Long, C., Chen, X., Jiang, L., Zhi, L., \& Fan, Z. (2015). Porous layer-stacking carbon derived from in-built template in biomass for high volumetric performance supercapacitors. Nano Energy, 12, 141-151. doi:https://doi.org/10.1016/j.nanoen.2014.12.014

Loomis, W. (1949). Photosynthesis - an introduction. Photosynthesis in plants, ed. by J. Franck and WE Loomis, 1-17.

Lourvanij, K., \& Rorrer, G. L. (1993). Reactions of aqueous glucose solutions over solid-acid Yzeolite catalyst at 110-160. degree. C. Industrial \& engineering chemistry research, 32(1), 11-19. 
Lu, X., Hanna, J., \& Johnson, W. (2000). Source indicators of humic substances: an elemental composition, solid state 13C CP/MAS NMR and Py-GC/MS study. Applied Geochemistry, 15(7), 1019-1033.

Marshall, C. E., \& Page, H. J. (1927). The Origin of Humic Matter. Nature, 119, 393. doi:10.1038/119393a0

Meyers, P. A., \& Ishiwatari, R. (1993). Lacustrine organic geochemistry-an overview of indicators of organic matter sources and diagenesis in lake sediments. Organic geochemistry, 20(7), 867-900.

Nagar, B. (1963). Examination of the Structure of Soil Humic Acids by Pyrolysis-Gas Chromatography. Nature, 199(4899), 1213.

Nelson, P., Dictor, M., \& Soulas, G. (1994). Availability of organic carbon in soluble and particlesize fractions from a soil profile. Soil Biology and Biochemistry, 26, 1549-1555.

Page, S. E., Rieley, J. O., \& Banks, C. J. (2011). Global and regional importance of the tropical peatland carbon pool. Global Change Biology, 17(2), 798-818.

Petrov, D., Tunega, D., Gerzabek, M. H., \& Oostenbrink, C. (2017). Molecular Dynamics Simulations of the Standard Leonardite Humic Acid: Microscopic Analysis of the Structure and Dynamics. Environmental Science \& Technology, 51(10), 5414-5424. doi:10.1021/acs.est.7b00266

Radwan, A., Davies, G., Fataftah, A., Ghabbour, E. A., Jansen, S. A., \& Willey, R. J. (1996). Isolation of humic acid from the brown algaeAscophyllum nodosum, Fucus vesiculosus, Laminaria saccharina and the marine angiospermZostera marina. Journal of applied phycology, 8(6), 553-562.

Sáiz-Jiménez, C., \& De Leeuw, J. (1986). Chemical characterization of soil organic matter fractions by analytical pyrolysis-gas chromatography-mass spectrometry. Journal of Analytical and Applied Pyrolysis, 9(2), 99-119.

Schnitzer, M. (1969). Reactions between Fulvic Acid, a Soil Humic Compound and Inorganic Soil Constituents 1. Soil Science Society of America Journal, 33(1), 75-81.

Schwartz, D., \& Asfeld, L. (1963). Structure of Carboxyl Groups in Humic Acids. Nature, 200, 569. doi:10.1038/200569b0

Shan, J., Brune, A., \& Ji, R. (2010). Selective digestion of the proteinaceous component of humic substances by the geophagous earthworms Metaphire guillelmi and Amynthas corrugatus. $\begin{array}{llll}\text { Soil Biology and Biochemistry, } & \text { 42(9), }\end{array}$ doi:https://doi.org/10.1016/j.soilbio.2010.05.008

Shi, Y., Matsunaga, T., Saito, M., Yamaguchi, Y., \& Chen, X. (2015). Comparison of global inventories of $\mathrm{CO} 2$ emissions from biomass burning during 2002-2011 derived from multiple satellite products. Environmental Pollution, 206, 479-487. doi:https://doi.org/10.1016/j.envpol.2015.08.009

Shulga, Y. M., Baskakov, S. A., Baskakova, Y. V., Lobach, A. S., Volfkovich, Y. M., Sosenkin, V. E., . . Kumar, Y. (2017). Hybrid porous carbon materials derived from composite of humic acid and graphene oxide. Microporous and Mesoporous Materials, 245, 24-30. doi:https://doi.org/10.1016/j.micromeso.2017.02.061

Sihombing, R., Greenwood, P. F., Wilson, M. A., \& Hanna, J. V. (1996). Composition of size exclusion fractions of swamp water humic and fulvic acids as measured by solid state NMR and pyrolysis-gas chromatography-mass spectrometry. Organic geochemistry, 24(8-9), 859-873. 
Sollins, P., Homann, P., \& Caldwell, B. A. (1996). Stabilization and destabilization of soil organic matter: mechanisms and controls. Geoderma, 74(1-2), 65-105.

Steelink, C. (1985). Implications of elemental characteristics of humic substances. Humic substances in soil, sediment, and water.

Stevenson, F., Fitch, A., \& Brar, M. (1993). Stability constants of Cu (II)-humate complexes: comparison of select models. Soil Science, 155(2), 77-91.

Sutton, R., \& Sposito, G. (2005). Molecular structure in soil humic substances: the new view. Environmental Science \& Technology, 39(23), 9009-9015.

Terashima, M., Fukushima, M., \& Tanaka, S. (2004). Influence of pH on the surface activity of humic acid: micelle-like aggregate formation and interfacial adsorption. Colloids and Surfaces A: Physicochemical and Engineering Aspects, 247(1-3), 77-83.

Titirici, M.-M., Antonietti, M., \& Baccile, N. (2008). Hydrothermal carbon from biomass: a comparison of the local structure from poly-to monosaccharides and pentoses/hexoses. Green Chemistry, 10(11), 1204-1212.

Titirici, M.-M., Thomas, A., Antonietti, M. (2007): Back in the black: hydrothermal carbonization of plant material as an efficient chemical process to treat the $\mathrm{CO} 2$ problem. ${ }^{\wedge}$ New J. Chem., 31, 787-789

Verma, L., Martin, J., \& Haider, K. (1975). Decomposition of Carbon-14-Labeled Proteins, Peptides, and Amino Acids; Free and Complexed with Humic Polymers 1. Soil Science Society of America Journal, 39(2), 279-284.

Visser, S. A. (1962). Production of Humic Substances in Decomposing Peat and Compost Samples. Nature, 196, 1211. doi:10.1038/1961211b0

Wang, J. P., Matthews, M. L., Williams, C. M., Shi, R., Yang, C., Tunlaya-Anukit, S., .. . Chiang, V. L. (2018). Improving wood properties for wood utilization through multi-omics integration in lignin biosynthesis. Nature Communications, 9(1), 1579. doi:10.1038/s41467-018-03863-z

Weber, J. H., \& Wilson, S. A. (1975). The isolation and characterization of fulvic acid and humic acid from river water. Water Research, 9(12), 1079-1084. doi:https://doi.org/10.1016/0043-1354(75)90105-0

Wikberg, H., Ohra-aho, T., Pileidis, F., \& Titirici, M.-M. (2015). Structural and morphological changes in kraft lignin during hydrothermal carbonization. ACS Sustainable Chemistry \& Engineering, 3(11), 2737-2745.

Wilson, M. NMR Techniques and Applications in Geochemistry and Soil Chemistry 1987. In: Pergamon Press: Oxford.

Xiaoli, C., Shimaoka, T., Qiang, G., \& Youcai, Z. (2008). Characterization of humic and fulvic acids extracted from landfill by elemental composition, 13C CP/MAS NMR and TMAHPy-GC/MS. Waste management, 28(5), 896-903.

Yan, X., Jin, F., Tohji, K., Kishita, A., \& Enomoto, H. (2010). Hydrothermal conversion of carbohydrate biomass to lactic acid. AIChE Journal, 56(10), 2727-2733. doi:doi:10.1002/aic.12193

Yang, X., Wang, H., Li, C., \& Lin, C. S. K. (2017). Restoring of Glucose Metabolism of Engineered Yarrowia lipolytica for Succinic Acid Production via a Simple and Efficient Adaptive Evolution Strategy. Journal of Agricultural and Food Chemistry, 65(20), 41334139. doi:10.1021/acs.jafc.7b00519

Zhu, Y., Chen, M., Li, Q., Yuan, C., \& Wang, C. (2017). High-yield humic acid-based hard carbons as promising anode materials for sodium-ion batteries. Carbon, 123, 727-734. 